\title{
Ageing well? Older people's health and well-being as portrayed in UK magazine advertisements
}

\author{
By Virpi YlänNe $^{1}$, Angie Williams $^{1}$ \& Paul Mark Wadleigh $^{2}$
}

\begin{abstract}
The media, including advertising, is an important source of information about health and ageing. Furthermore, advertising makes certain discourses, vocabularies and imagery available as resources for age and health identity formation for older adults. The aim of this study was to investigate qualitatively the prominent themes relating to health and ageing that emerged from a sub-corpus of 140 British magazine advertisements depicting older adults. We focus on how these depictions construct health identity in older age through their underlying discourses. The six main themes included solutions to health problems; maintenance or regaining of independence and quality of life; managing risks; staying younger, healthy and active; taking pride in appearance; and discourses of responsibility and choice. The most prominent underlying discourse was the possibility, necessity and desirability to take positive action to maintain health and well-being in older age. We relate these findings to current societal discourses of active ageing and anti-ageing.

${ }^{1}$ Virpi Ylänne, Angie Williams, Centre for Language \& Communication Research/ENCAP, Cardiff University, Cardiff, Wales, UK.

${ }^{2}$ Paul Mark Wadleigh, The Edward R. Murrow College of Communication, Washington State University, Pullman, WA, USA.
\end{abstract}


International Journal of Ageing and Later Life

Keywords: Advertising, images of older people, health, active ageing, anti-ageing.

\section{Introduction}

Our lifespan identities, like other aspects of our identities, are subject to our own individual evaluations and (re)assessment in terms of how old we are (or feel) and what lifespan stage we inhabit. But as part of our social identities, age or lifespan identities are formed by social processes and influenced by societal expectations, some of which are available in the media, including advertising. Health identity is an important aspect of our (age) identity and our main focus in this article. We approach our data from a broadly social constructionist perspective which sees (age) identity as a socially constitutive process (Gergen 1985) involving identification work by individuals. Arguably, then, consumers of adverts may identify with or disassociate themselves from images in them. Advertising not only makes it possible for older people to use health information designed by others, it also makes certain discourses, vocabularies and imagery available as resources for age and health identity or identification that enable older people and their families to manage and think about their own health.

Consumers are neither passive targets of advertising, nor are adverts ideologically neutral. They not only represent "reality" linguistically and semiotically, they constitute it. It is also worth bearing in mind that adverts are typically created by people who are not old themselves. Hence for the author(s) of the kinds of adverts we consider here, the adverts constitute representations and discourses of the "other" which is also a potential subject position available for the reader. Fairclough (2001) describes how advertisements work ideologically: advertising discourse builds relations between the product/advertiser and the audience; it builds an image for the product; and it constructs subject positions for consumers. For example, many of the adverts under analysis in this article are specifically targeted at older individuals. They position older consumers as certain kinds of individuals through the construction of specific age-related needs, pursuits and problems.

We aim to explore how this is done. Our broader research project (see Acknowledgements) has examined types of images of older people in 
Older people's health and well-being as portrayed in UK magazine advertisements

print media (and TV) advertisements more generally (see Williams et al. 2010, in press), but our focus in this article is on advertisements that contain health-related messages that appeared in British magazines over a five-year period (1999-2004; this was a period five years prior to the start of the project, which spanned 2004-2007). Thus, we examine what messages and themes of ageing and health emerge from the texts and the accompanying visual imagery of these print media adverts and how they may construct health and body agendas for older people.

Older people's perceptions of health and their health identity as an ageing person derive from various sources of health communication (Piotrow et al. 1997). In contemporary society there are numerous sources of health information, such as service providers, books and publications, the internet and the media. The media is a particularly important vehicle for health information (Atkin \& Wallack 1990). Some of this information is explicit and planned as in media health campaigns, but some are more indirect and implicit, unplanned and even unforeseen. Therefore, the messages available in advertising can be both direct and indirect in that they can focus in on particular health issues or they can inform about health and well-being consequentially while addressing another seemingly unrelated issue.

Apart from the rather obvious function of informing people and promoting particular products, advertising sets priorities for health in ageing. Advertisements show older people what they might expect as they age. In this way, advertising influences how older people construct themselves as ageing individuals as well as their conceptualisation of the ageing body and the health and welfare challenges of ageing. But on the other hand, advertising can also give false promises about ageing and might force older adults to construct themselves as ageless individuals. It is our intention in this article to examine the variety of health and well-being messages in advertising. Before that, we review some literature relevant to the current study.

\section{Portrayals of Older People in the Media}

Media images of older people have been studied for some years. There has been fairly extensive research into how older adults are portrayed in 
International Journal of Ageing and Later Life

various media (see Robinson et al. 2004, for a review). For example, TV programmes (e.g. Harwood \& Anderson 2002; Harwood \& Giles 1992; Kessler et al. 2004) and TV commercials have been scrutinised (e.g. Lee et al. 2007; Roy \& Harwood 1997; Simcock \& Sudbury 2006; Swayne \& Greco 1987). More pertinent to this study, print advertisements have also generated research interest over the last 20 years and more (e.g. Bramlett-Solomon \& Wilson 1989; Carrigan \& Szmigin 1998; Harwood \& Roy 1999; Robinson et al. 2008; Ursic et al. 1986) as has magazine and newspaper portrayals of health and illness in old age (e.g. McKay 2003; Rozanova 2006). Examining images of older age in advertising can be partially driven from a realisation of the increasing importance of the "grey market" (e.g. Carrigan \& Szmigin 1999a; Peterson 1992).

Many of these studies rely on content analysis as their methodology and as such provide valuable information on general patterns of representation, but they typically don't offer in-depth analyses of the messages. Before examining such studies conducted in the UK context, we provide a brief review of the results of some content analytic studies with a focus on findings that apply to health and welfare for older people.

Results from content analytical studies have suggested that not only are older people (especially women) under-represented in general media (news media and TV), but that when they do appear it has tended to be in stereotype confirming roles (Peterson 1992, 1995; Robinson \& Skill 1995; Smythe 1996). However, it has been found that the advertising media, as opposed to the general media, tend to portray older people positively rather than negatively (Harwood \& Roy 1999; Simcock \& Sudbury 2006). Thus, older people in adverts are often depicted in terms of positive stereotypes.

Several studies (Miller et al. 1999, 2004) found that "Golden Ager" (i.e. older people as relatively active, glamorous and competent) and "Perfect Grandparent" portrayals (older people in grand-parenting roles, typically in a family setting) (see Hummert et al. 1994) were rather typical of TV representations of older people. Our own recent study of magazine ads endorses this finding of the prominence of such images in the advertising media (Williams et al. 2010, in press). Golden Agers were frequently found in our sample of British print media ads (36\% of our sample of 221 ads). But in addition we found that "Copers" (older people coping with a 
Older people's health and well-being as portrayed in UK magazine advertisements

mobility or health problem) were quite frequently portrayed, too ( $24 \%$ of the ads). Both these types of representation rely on associations between health and ageing. The former category depicts positive ageing, i.e. healthy and active older lifestyles, the latter alludes to physical limitations (and decline) brought about by ageing but promotes action, responsibility and ways for older individuals to cope with these limitations.

In terms of products, it has been fairly consistently found that in advertising older people are linked with a limited set of product types. For example, they are more often associated with food and drink than technological devices or cars (e.g. see Miller et al. 2004). Health products are important here as older people (typically indexing longevity) are used to sell the health benefits of certain foods such as olive oil-based margarine (Williams et al. 2007). Another dimension that has been explored in content analytical studies is the environment or setting of the advert and older people are frequently depicted as being at home. In terms of gender, women are represented more than men in terms of relational contexts; it has been suggested that US print advertisements often depict older characters with their spouses, colleagues and in service-related relationships (Harwood \& Roy 1999).

In the existing literature, very few studies have systematically examined depictions of older people in advertisements placed in magazines designed for older readerships. There are some notable exceptions and we will discuss these and their findings as they apply to older people's health and welfare next.

In one such study, Roberts and Zhou (1997) examined adverts in USA Modern Maturity magazine. They found that the older people were almost always portrayed in important roles, but they were most often depicted in home settings. It was those aged $65+$ who were depicted as "sedentary" while those younger than 65 were portrayed as active. Almost all older people in the ads in this publication were shown to be in good health.

A British study by Carrigan and Szmigin (1999b) is to our knowledge the only one apart from our own (Williams et al. 2010) which has attempted to compare the images of older people in advertisements in mainstream newspapers and magazines to those found in publications designed for older people. Comparing the Daily Mail, Daily Telegraph, Good Housekeeping and Women's Journal to Choice, Saga Magazine, Goodtimes and 
International Journal of Ageing and Later Life

Active Life, Carrigan and Szmigin explored the relative distribution and positivity of portrayals of older people across the two data sets.

Their findings echo those of previous research in that the older people were under-represented in mainstream publications, but they found this not to be the case in publications designed for older people. More pertinent to our current concerns, older adults were predominantly characterised as "favourable" (competent, looking active and enjoying an activity) in both mainstream and the specialist publications. In other words, older people were depicted as active and enjoying good health. In terms of the products associated with older people, mainstream publications tended to feature older people in ads for food, household appliances and health products. In magazines for older people, in contrast, a third of the ads featuring older people were for disability and mobility products (e.g. stair-lifts and orthopaedic beds). Ads for financial services were also fairly frequent as were ads for health and medicine.

Thus, we can see that advertisements that draw an association between ageing and health are very frequent in publications for older people. It has been shown (Williams et al. 2007) that many ads for common everyday foodstuffs in mainstream magazines also draw on associations between increasing age and health concerns. In a content analytical classification scheme these associations are in danger of being lost if the analysis records the data in terms of "product" (such as food and drink) and thus leaves the health association unrecorded. A closer textual and semiotic analysis offers a more holistic outcome as it enables the examination of the portrayal of the older person in the full context of the ad, including the product, the setting and the persuasive strategies that are used.

An example of a close, thematic analysis of representations of older adults and health in the media is a study by Rozanova (2006). Her focus was newspaper articles in a leading Canadian newspaper which covered health, illness and ageing (old age). Three main themes emerged. Firstly, the articles built an association between ageing and disease, bodily decline and general worsening of one's health. Secondly, individual responsibility for healthy ageing was highlighted, including the reverse scenario of inappropriate (unhealthy) lifestyle choices as being direct causes for health problems in older age. Thirdly, the costs of (un)healthy ageing were foregrounded, both to individuals themselves but also to society at large in 
Older people's health and well-being as portrayed in UK magazine advertisements

the case of ill old people. The first two themes in particular are relevant to our investigation of how older age and health might be linked in adverts which promote healthy living and healthy ageing and we shall return to these in our analysis below.

There are a few studies that have investigated in-depth representations of old age in the British media. For example, Featherstone and Hepworth (1995) carried out an often-cited longitudinal case study of the (Retirement) Choice magazine. The magazine, from its conception in 1972, explicitly attacked the traditional ageist image of retirement in Britain, namely that of uselessness and passivity. Instead "the promotion of the benefits of an active, positive ageing lifestyle where the consumption of goods and services has an integral role to play in the battle against ageism" (Featherstone and Hepworth 1995: 40) has predominated, together with relatively glamorous, youthful, fit and healthy images of middle-aged and older people.

In another UK study Bytheway (2003) analysed the contents and imagery found in an issue of YOURS magazine, a weekly magazine targeted at older readers. In the features coverage Bytheway found "familiar images of later life: reflection and fulfilment, travel and activity, and advice and support" (Bytheway 2003: 44). The advertisements form the largest visual representations of later life that appear in the magazine, with clothing; travel/holidays/cameras; equity and medicines/food supplements/cosmetics being the most frequently advertised products. Models were judged as quite young - less than 50 years old - which seems incongruent in some cases as they did not appear to need the products they were advertising, such as stair-lifts. Bytheway concludes that through its imagery and other coverage YOURS magazine provides guidance for its readers on what active steps can be taken to fight the challenges and inevitabilities of older age. Such images can help set an agenda for successful ageing that is not just a template for how to survive old age, but which encourages the perception that people can thrive in old age. In line with this argument, he suggests that older people are persuaded that there are alternative lifestyles to be selected and enjoyed.

Relating to the notion of constructing alternative lifestyles in older age, recent research and theory in social gerontology has focussed on the (ageing) body as a social construct (e.g. Faircloth 2003). Indeed as long ago 
International Journal of Ageing and Later Life

as 1991, Giddens argued that in late-modern society "the self" - including "the body" - can be considered a "life project". Perhaps, then, visual representations and media imagery prompt social comparative processes whereby we monitor how we are doing (for our age) compared to others of a similar age and social standing. It is possible that older consumers use these images as part of their life project. In late-modernity it seems that ageing is eventually inevitable - despite the ideology of "the anti-ageing enterprise" (Vincent et al. 2008). But for those in midlife, ageing can appear to be more about choice than inevitability. That choice is exercised through the consumption of goods and services that (are believed to) correct, delay or hide evidence of ageing, as is evident in many of the advertisements we consider here.

Moreover, Faircloth (2003) and others (e.g. Hughes 2000) have noted how late-modern society has medicalised the body so that we perceive disease as a deviant state of affairs that needs regulation and control (Burchill et al. 1991; Turner 1995). Decline in ageing falls under this remit: age-related immobility, disease and illness are seen as deviant and something one should endeavour to correct. We shall return to this notion later.

Considering the issues of body, health and decline within the context of an ageing population where "a widespread secular improvement in life expectancy in old age and in late-life healthiness seems incontestable" (Gilleard \& Higgs 2000: 160), a health focus in advertisements depicting older people seems to us an important avenue of research. We seek to use a wider sample than previous UK-based research and focus on advertising itself rather than on other magazine content. We also seek to elaborate and extend our analysis beyond a simple content analysis - we therefore undertake closer textual, thematic and semiotic analysis in this article to extend our own (Williams et al. 2010) and others' previous content analytical categorisation.

Based on a corpus of print media advertisements depicting older people, we examine what kinds of products are advertised and what kinds of health-related promises are made about the benefits of using the product. Our analysis will focus on the emergent thematic strategies and underlying discourses of the adverts; in other words, we focus on how healthrelated themes are realised in the adverts rather than on content analytical 
Older people's health and well-being as portrayed in UK magazine advertisements

distributional facts. Moreover, we explore the body-project and health and lifestyle options and implications for older consumers that our data present. In summary, we aim to answer the following set of research questions:

RQ1: What assumptions are made about older people's health and well-being?

RQ2: With what products are issues of health and well-being in older age associated?

RQ3: What themes emerge as prominent in the adverts that have a health and well-being focus?

RQ4: What underlying discourses about health and ageing are evident in these ads?

RQ5: What, if anything, can be said about societal assumptions about older people's orientation towards their health and well-being on the basis of these ads?

\section{Method}

Before describing the current study, we describe how we arrived at an overall sample of British magazine advertisements used for the wider research project. We consulted Brad Monthly Guide to Advertising Media (2004), Willing's Press Guide to UK Media (2003) and the National Readership Survey (National Relationship Survey 2003) to access information about readership profiles. We followed the practice often cited in previous research on magazine advertising (e.g. Harwood \& Roy 1999) regarding the need to cover different types of magazines, and eight basic categories of magazines were identified within the following schemata: general, men's, women's, sports, home, business, young audience and older audience. We aimed to cover some of the most popular magazines but also different genres and age-groups.

In this way target publications for our sample of British magazines were identified. The resultant sample of magazines included one weekly publication, Radio Times (home), one fortnightly magazine, The Economist (business) and nine monthlies: Saga Magazine (older), ASDA Magazine (general, home and family), Marie Claire (younger women), Rugby World (men, sport), Men's Health (men), FHM (younger men), Good Housekeeping 
International Journal of Ageing and Later Life

(women, home and family), Family Circle (home and family) and BBC Good Food (home).

We examined magazines from June 1999 to May 2004, a five-year period with six years of publication. We collected nine monthly, one weekly and one fortnightly magazine for each of the six years. To create a more manageable sample, a single composite year was compiled using stratified random sampling. For example, for December of our composite year, issues were randomly selected from the December issues in our sampling frame. The composite year was composed of publications from: January 2002, February 2000, March 2004, April 2004, May 2003, June 1999, July 2000, August 2003, September 2002, October 2001, November 2001 and December 1999. Thus, each year in our sampling frame appeared twice in our composite year.

The resultant 121 magazine issues were then analysed for any advertisements a quarter of a page and larger, containing a "recognisable" human figure appearing to be 60 years or older. Although some earlier studies have chosen a cut-off point of 50 years, we chose 60 years because it has been found that people across different age ranges judge "old age" to start after the chronological age of 60 years (Garrett \& Williams 2009). Therefore images of people in their fifties might be seen to depict "middleaged" rather than "older" adults, especially in the context of an ageing population and increased lifespan. Two researchers (aged 42 and 54 years) independently scrutinised our initial database for adverts depicting people 60 years and over. The older person(s) in the advert were judged either to be 60 years or over or not (a binary yes/no coding). Inter-coder reliability was calculated using Cohen's Kappa, which gave a result of 0.85 . Disagreements in coding were discussed and resolved so that only adverts that both coders agreed depicted people 60 years or over were included in the final sample.

A "recognisable" human figure meant enough of the face was visible to be reasonably certain of the character's sex, age and expression. Isolated photographic images of human hands, for example, even though they may have been clearly hands of an older person were not sampled, neither were cartoons nor puppets. This resulted in an initial total of 253 ads with an older person featured as one or more characters. These were further scrutinised and duplications were eliminated. This resulted in a final 
Older people's health and well-being as portrayed in UK magazine advertisements

corpus of 221 advertisements meeting all of the criteria. Because our wider research programme focuses on representations of older people in advertising, only adverts that featured (an) older adult(s) were collected. Adverts for health-related products (even if age-salient) that didn't contain an older person were therefore arguably missed from the sample.

\section{Selecting Health-Related Adverts}

Our database of 221 adverts was previously content analysed for categories, such as product, tone of advert (on a scale from derogatory to positive); type of portrayal; rhetorical scheme; the setting of the advert; the sex of the character(s); and the presence or absence of humour (see Williams et al. 2010). The results from the content analysis showed that $14.5 \%$ of the ads were for "medical or health" products. But this figure does not include adverts for other products that have a strong connection to health, mobility and welfare issues for older people and would therefore be of significance to this study. Some obvious examples that would not be found if we adhered to our initial coding of medical products alone are items such as help \& support (e.g. stair-lifts) which comprised $26.2 \%$ of the ads and foodstuffs that claim a health benefit.

For this study, then, adverts that relate to health and well-being more broadly defined were selected. Criteria for selection were: that the ad related directly to health or medical issues, mobility or disability, food supplements, and food and drink items that included a health message, general consumer goods that included a health or longevity message, and more minor cosmetic ads (e.g. wigs and skin-care) were also included. Overall, 63.3\% (140) of the adverts in our data base were selected by the researchers working together. The adverts that we examine here were drawn from the following product categories which we had identified earlier in our research: help/support, food and drink, medical/health, cosmetics, household and professional services.

The adverts were scrutinised qualitatively through emergent theme analysis, guided by Constant Comparative Method (Glaser \& Strauss 1967; Strauss \& Corbin 1998). This method is part of a Grounded Theory approach which seeks to develop theory inductively from the data itself. In practice, we examined our data corpus advert by advert, noting the thematic focus of the adverts. We categorised the data according to the 
International Journal of Ageing and Later Life

most salient health messages. Each advert was compared to previously classified adverts and new themes were devised as necessary. Both the text and the visual imagery were taken into account and two researchers worked together through this process. This was repeated in an iterative process until all adverts were classified and the researchers were assured that all main themes had been captured. This method of analysis was then combined with the examination of the language/discourse in the advert. Thus when we discuss the health-related themes below, we look at how those themes were discursively formulated through language. Six main themes emerged and these are described below.

As the aim of this study is to offer a qualitative and critical description of the advertisements that have a health and well-being focus, we will not offer quantitative information (apart from percentages) or statistical details about the associations between different variables regarding the adverts.

\section{Findings and Discussion \\ Products and Presentation}

In our database, typical products that are linked to health issues for older people include: mobility aids (e.g. stair-lifts, scooters, walk-in baths) (36.4\%); food supplements (e.g. vitamins, Gingko Biloba) (5.7\%); food (e.g. margarine, bread promoted as health food) (7.9\%); vacuum cleaners (with emphasis on light weight) (5\%); telephone/security aid (6.4\%); sheltered and retirement housing or respite care (12.9\%); lifestyle enhancers (products and devices related to teeth, eyes, ears, heart, bladder weakness and cosmetics) $(17.9 \%)$ and health insurance $(2.9 \%)$. Only two adverts for other general consumer products drew an association between an older person and health. These were an advert for sports footwear and an advert for swimwear, both emphasising the health and longevity benefits of exercise.

The most common category of adverts was mobility aids (special beds, stair-lifts, walk-in baths, scooters and so on) and the vast majority of these were found in Saga Magazine. These ads make up a fairly tightly defined genre. They appear informative - the information seems to take precedence over any other kind of content. For example, they are rarely if ever humorous and they are not particularly visually engaging. They 
Older people's health and well-being as portrayed in UK magazine advertisements

declare their basic information using headlines and by-lines and they usually use a representative who is demonstrating the product.

Typically the older person depicted using the product looks straight into the camera, thereby creating a visual form of direct address with the viewer of the image/reader of the advert. These types of images are what Kress and van Leeuwen (1996) term "demand" images: "the participant's gaze demands something from the viewer, demands that the viewer enter into some kind of imaginary relation with him or her" (Kress and van Leeuwen 1996: 122). Sometimes the ad representatives are well-known TV personalities who are now old - people the readers know and can trust known in the advertising literature as "celebrity endorsers". For example, actress Dame Thora Hird says, "With Churchill's Relaxchair, I don't have to struggle to sit down or get up any more". Among other things, such models may help older people to admit that they need help: if Thora Hird admits that she struggles, then so can I. At other times, the endorsing figures are supposedly members of the public representing satisfied customers and appearing as happy and/or relaxed.

\section{Problem Focus}

One device that is commonly used in advertising texts to all consumer groups is to define the consumer as having problems for which the advertised product is presented as a solution (Winter 1982). What is significant about our data corpus is that the problems appear to be related to ageing, the underlying discourse is therefore about presenting ageing itself as problematic in terms of health and well-being. These problems range from more serious mobility issues to the hassles of needing reading glasses and dentures. We now provide some examples of adverts of this kind.

One ad for a walk-in bath declares "If you are having problems bathing you can suffer a real loss of independence". Another ad claims to be "the most complete answer to bathing difficulties". Similarly, "if you struggle to get in and out of the bath...you'll love my friend BATHMATE". Yet another one states "it's not you with the problem. It's your bath" - thus taking away the agency of the older consumer, as if to suggest that it is the environment that needs to adjust to the individual's needs rather than the other way round. "Vulnerable?" asks an ad for a personal alarm system 
and promises, "our personal alarm system would enable you to call help at any hour of the day or night - simply by pressing the button". Rarely do advertisers explicitly suggest that these aids might be for disabled or infirm consumers as the following one-off example does: "Simply stairlifts and Scope [name of charity] are in partnership to help disabled people and improve the lives of the elderly and infirm". Interestingly, "elderly" and "infirm" are linked in adjectival co-occurrence (see Mautner 2007).

The visuals that accompany these advertisements for walk-in baths and the like are not of people who are having problems or who are obviously disabled, very elderly or infirm. On the contrary, older people who appear in these ads often look fit and glamorous and appear to be "young-old". As previously noted by Bytheway and others, these characters do not look as if they obviously need the products they are advertising. But the connection between older age and physical limitations or vulnerability is built through imagery by presenting the older individual in a grandparent role together with grandchildren or through physiognomic cues of grey hair and "older style" dress, for example.

A minority of ads make fear or sympathy appeals (such as an ad for a cancer charity) which feature less glamorous, more "negative" and vulnerable, typically female, characters. For example, "June" (in an advert for Aid-Call personal alarm) has had a fall, she looks distressed, and is wearing a nightdress. But a closer inspection reveals that she is rather attractive and well made-up. These adverts seem to address readers who share an understanding (or an expectation) of certain kinds of physical limitations that accompany ageing; perhaps they or a family member has a similar problem. Thus, the answer to questions such as "Do you struggle to get in and out of the bath?" is presumed to be "yes" (or, alternatively, "yes, mother/father does"). While addressing a need, they confirm negative expectations of mobility and health in older age. On the other hand, these ads and their at times relatively glamorous models might be construed to demonstrate how even severe problems of older age and immobility can be managed.

\section{Problem Solutions and Benefits}

The overarching message of these adverts is that the proposed difficulties and problems can be overcome or at least satisfactorily managed - with 
Older people's health and well-being as portrayed in UK magazine advertisements

the help of the product advertised. This is achieved through several categories of benefits of these products that the adverts highlight. The first can be characterised as ease and comfort: they emphasise that life will be made "easier and safe" (e.g. getting in and out of the bath with BathKnight). The products are also described as "simple and easy", or the emphasis is on "comfort and safety". For example, orthopaedic beds offer "ultimate comfort". Similarly, "the Relaxchair soothes away aches and pains". Interestingly, the range of problems that a recliner is presented to ease is impressive: "arthritis, stress and anxiety, rheumatism, backache, fluid retention, circulatory problems and much more". Lightweight, easy to use vacuum cleaners also fall into this category. These are peddled by older women who are visually very stereotypical (of ageing housewives?) with curly grey perms and old-fashioned dresses.

The second category is maintaining or regaining independence: "Why struggle when you could be enjoying the pleasure of a long hot bath again" reads an ad for a walk-in bath. Similarly, "thanks to Bath-Knight's unique design, getting in and out of the bath can be just as easy again". So a sense of regaining that which has been lost or maintaining what one has seems to be emphasised. Freedom and independence are important words used here, as is the use of "again" with a connotation of a return to past pleasures (enjoyed when younger). For example, a stair-lift will allow you to "regain the freedom of your home". "I really used to enjoy having a bath" claims one endorser for a bathing product, and later "Premier Bathrooms has helped me regain my independence". Other examples include: "Let your bathing difficulties be a thing of the past"; "Retain your independence with ...24 hour monitoring service". The use of words beginning with "re-" have the same connotation of returning to something that is lost (deriving this meaning from the prefix in words such as regain). A company of retirement builders claims that with their help you can "maintain your independence". The underlying message seems to be, then, that of continuity: despite advancing years, the quality of life in terms of independence can be maintained. Lack of independence is, of course, one of the main concerns of ageing individuals, so these products and adverts address this need, and arguably gain their success precisely through addressing these worries and fears. 
International Journal of Ageing and Later Life

Apart from maintenance of independence, the ads promise even greater benefits. A third type of benefit refers to quality of life. Enjoy a better "quality of life" states a company specialising in mobility aids; "forget bladder problems and enjoy life to the full" suggests an advert for incontinence underwear. Furthermore, a walk-in bath promises to "change your life" with the added advantage that "your grandchildren will hardly know it is there". Therefore this aid will not disrupt family life or cause difficulties for other users. Other examples with an up-beat tone are: "Happiness is Healthspan quality" in an ad for a food supplement; "enjoy your retirement" and "relax and do only the things you love; while we do all those things you hate" in an ad for retirement living. Retirement lifestyle is constructed here as relaxation, but also activity, although notably only enjoyable (quality) activity.

The fourth category of benefits is peace of mind, which is often associated with the well-known persuasive strategy - appeals to fear (as alluded to above). In an ad for a personal alarm system this is formulated: "Mrs. Hope knows that help is coming - would you?", accompanied with a picture of "Mrs. Hope" lying on the ground outside on the lawn (perhaps having attended to her garden), with her eyes closed but her finger on the button of the alarm placed round her neck for easy access. These ads promise to appease older adults' fears and anxieties (cf. lack of independence above). "Peace of mind" is brought by a heart (ECG) monitoring device that promises freedom from a "life of constant anxiety". So, again, the product is presented as a solution to an age-related problem. Incidentally, the target audience for personal alarm systems in particular and other "peace of mind" products might be children of ageing parents, as demonstrated in one ad which states, "Sheila thought it would never happen to her... thankfully her daughter didn't", accompanied by a picture of "Sheila" lying on the floor, eyes closed, at the bottom of the stairs (implying a fall), with her finger on the alarm button.

Ostensibly, addressing older people, one ad alerts readers that "[i]f you have an accident when you live alone, the consequences can be serious". And another: "No-one would have heard June calling for help ... if it hadn't been for her Aid-Call" and "[1]iving alone doesn't worry George or his family ... especially now that help is always at hand". Peace of mind is 
Older people's health and well-being as portrayed in UK magazine advertisements

presented as a benefit not just for ageing individuals but for their families, too.

In line with this peace of mind theme, and with a picture of a couple, an ad for a health screening scan shows a road sign illustrating a roundabout with straight on directions to "peace of mind" in bold and a left turn to aneurysm, second left to cancer and right to heart disease. The use of the traffic sign illustration invokes the idea of life as a journey with different potential directions. The endorser in the ad explains that he had a potentially fatal condition that was detected by the scan. The subsequent operation prevented the alternative, which would have "brought my life to a close before I had time to really enjoy myself". Peace of mind message can also co-occur with a more minor - albeit age-related health problem such as incontinence. An ad for incontinence pads declares that by using the product, one can "just forget 'it"'. This bladder weakness is described as light and the photo is of a woman enjoying herself outdoors with friends.

The peace of mind theme, then, seems to involve the advertised product offering protection from potential risks of accidents such as falls, unknown callers on the door, or as yet undiscovered health problems. In these ads, the risks and problems are presented as increasing with age or linked with age-salient living conditions, such as living on one's own. We could also label this sub-theme or discourse as "managing risks in older age". That risk in older age is evoked for advertising purposes is not surprising, taken the prominent discourse of risk in modern society as a whole (e.g. Beck et al. 1994), where much of our everyday activities are construed as minimising or managing risks of various sorts. Here, ageing with increasing frailty, declining health or living on one's own are the prominent risk inducing factors.

Another theme is that of staying younger, healthy and active. A range of advertisements are targeted at people who are not having difficulties but who are ageing, and the ads are about investing in a healthy lifestyle in order to "age well". In this category are ads for food supplements - showing a smiling "Golden Ager" (or third age; Laslett 1996) type couples. "Happiness is Healthspan quality" is the heading of one such ad. The same couple appear in a number of these ads (suggesting advertisers' reliance on an image bank), sometimes with a child (representing a grandchild); they always smile and look happy. The use of these kinds of 
International Journal of Ageing and Later Life

images invokes an intergenerational "stake". By using grandchildren they imply that older people have a familial duty to keep active and healthy. There is little text of any consequence beyond a listing of products, suppliers and so on in these adverts.

With the assumption that many middle-aged and older people are reasonably healthy and wish to remain so, some food products are also linked to health. One advert in this category features a named couple, husband and wife. He stands dressed in sportswear behind his rather homely looking wife, Sheila. She is said to have "tried him on Benecol". Further on, Sheila says, "I put Alan on Benecol..." Alan is passive in this ad and portrayed as being engaged in more light-hearted activities, with his wife being in charge of the serious issues, here food and diet. Interestingly, the phrase "put on" is more usually associated with medicine rather than a foodstuff (such as, "the doctor put him on a course of..."). There are likely to be gender issues here as women are traditionally seen as the keepers of family health and well-being (Brubaker 2007; Saltonstall 1993) and therefore it is women as wives or long term partners who are likely to be the principal targets of this advert.

In adverts for another brand of margarine, Flora, users are quoted to say that their cholesterol has dropped (with some exact figures given to emulate scientific and medical discourse of facts); "good news for anyone trying to maintain a healthy heart". The consumption of the product is presented as a lifestyle choice. An ad for Burgen bread, branded as healthfood, shows a woman on her bike, dressed in sports wear. The product is presented as "a natural choice" and it is interesting that an older model has been chosen to represent well-being. The ad states: "what we eat and drink has a great impact on how we feel and our general well being". An ad for Quorn products depicts grandparent figures, eating with their granddaughter, enjoying "healthier, more energetic life" and the captions "enhancing your life", "looking good" and "feeling great" within the text cumulatively endorse the product as having benefits which go far beyond nutrition (see also Williams et el. 2007, who discuss the health and age associations in ads for Olivio/Bertolli margarine).

Finally we find a theme of pride in appearance. There are only a few adverts in our database that focus on appearance and cosmetic issues. One example is an ad for a denture fixative cream which depicts a close-up of 
Older people's health and well-being as portrayed in UK magazine advertisements

an ageing couple kissing, with the caption "Make the earth move. Not your dentures". The product is offered as a solution to wobbly dentures which may "restrict your confidence and your fun". The positive aspect of this ad is the possibility of romantic enjoyment by people who, because of their age, need dentures. The negative side is the message that aid is needed for care-free enjoyment.

In our sample, there is only one advert for an anti-ageing cosmetic cream, which is for "re-densifying moisturiser to plump up thin and sagging skin". The product is depicted to be for "mature skin" (appearing as a descriptor on a tub of the product within the ad) and the protagonist is identifiable as a grandmother whose cheek is being pinched by a grandchild, represented by a plump hand of an infant. Ads for antiageing creams typically feature middle-aged women and that is why they were not picked up in our sample, so this one is an exception. It is likely that the model was used to signify "maturity", to align with the product. That an older woman's skin is thin and sagging seems to be taken as a given in this advertisement and a promise is made to "improve skin density by 10 years", rhetoric much used in cosmetics advertising (see, Coupland 2000). The common sense assumption endorsed in such advertising is that ageing women wish to use products to help them appear younger, and promises are made of consumerised solutions for "turning back the clock" (Coupland 2007).

Another advert is for cosmetic surgery which features a couple in embrace, with a caption underneath: "Now we're over 50 Cosmetic Surgery is our little secret of looking and feeling great". In the text next to the couple we have: "Affordable personal improvement for over 50s who want to look \& feel good". It is noteworthy that the couple are not especially old, but in the age bracket where visible signs of ageing appear. The woman in particular can be considered at a borderline for our sampling. The male looks older than the female, with greying hair and a receding hairline. Cosmetic surgery is advertised as a lifestyle product, with "quality after-care in a luxury spa". So this kind of product, although now easily available, may still be a luxury for most people.

Three ads in our sample were for non-health-related products, the first of which is an energy drink Lucozade (promises vitamins) which is said to give you "the oomph!". Ads for Adidas sports shoes and Speedo swimwear 
International Journal of Ageing and Later Life

were both found in the magazine Men's Health. Mr. Singh (who appears to be a real person) advertising sports shoes at age 92 is presented as an exceptional individual who regularly participates in marathon running events. As such he provides a positive image for the possibilities of old age. On the other hand, his physical condition could be found too exceptional and thus unattainable by most people. The swimwear ad is a very positive and striking image of a fit and slim-looking older man in swimming trunks; the image of the man walking alongside a swimming pool is credible and potentially encouraging. The rationale for the older model, though, seems to be to represent endurance, to index longevity and the potentially long life of the product: "Old age. It comes to every swimsuit eventually. But to Endurance swimsuits it comes much later in life". Perhaps old age itself can be postponed? This certainly seems to be the underlying message contained within this and many other ads.

\section{Discourses of Responsibility and Choice}

Some ads suggest that "you" - the consumer - are responsible for your own (and your family's) health: "take charge of your bladder problem" urges one ad. Henry Cooper, a well-known retired British boxing champion, says "Don't get knocked out by the flu", as he urges older people to get their flu jabs. Note the imperative mood in these ads, invoking a moral duty (going beyond just choice) for an ageing individual to take action. An ad for Bupa (private) hospital poses the question "When should you start to do something about your health?". Flora pro active margarine is allegedly "good news for anyone trying to maintain a healthy heart". "Interested in a healthy retirement?" asks an ad for Research into Ageing, a research charity. These ads connote agency, the allusion is that people are not passive victims of ill-health in older age. The adverts also appear to place the burden of responsibility on the consumers. They often imply that older adults owe it to their family to take care of their health and thus to enjoy an active and healthy old age. This (as the questions posed in the adverts indicate) is a lifestyle choice - a choice that is presented as obvious and unproblematic, as common sense even.

Relatedly, Jolanki (2008) found that older individuals (in their 70s and 80 s, taking part in focus group discussions) tended to agree with the notion of individual responsibility for health and their ability to influence 
Older people's health and well-being as portrayed in UK magazine advertisements

their own health in older age. As Jolanki points out (also citing Crawford 2006: 402), "people define themselves and others at least in part by their "healthy' or 'unhealthy' behaviour" (Jolanki 2008: 66). The advertisers of some of the products discussed above are constructing the consumption of certain foods or food supplements or the undergoing of health-related interventions as "healthy" behaviour. On the other hand, some older discussants in Jolanki's study articulated "fate discourse", linking older age with inevitable health problems, thus limiting their own agency and responsibility. The advertisers of the many mobility and other aids in our data can be seen to echo the sentiments of this discourse and to an extent normalise them as expectations of advancing years, compounded by the sheer plethora of protagonists in the adverts reporting having (had) "problems". But of course through the advertising industry, consumers are encouraged or even instructed to take responsibility to manage the problems (through consumption), as discussed above.

In a similar vein, Rozanova (2006) demonstrates how in her Canadian newspaper data, "although the risk factors causing unhealthy behaviour are pointed out, the locus of responsibility for one's health remains with the aging person herself" (p. 122). She elaborates on the moral dimension of these texts that imply that unhealthy lifestyles lead to unhealthy ageing, which is sinful, whereas healthy lifestyles and healthy ageing is presented as virtuous (p. 127). These ideas could be linked to the underlying discourses of our adverts, too, even if they are not so explicitly articulated in our texts.

\section{Conclusions: Ageing well?}

Our initial Research Question asked what assumptions were made about older people's health and well-being in these print media adverts. From a qualitative examination, it emerged that an underlying assumption of decline as well as risks were present. In terms of products, mobility aids and furniture designed to provide comfort predominated. Other notable products were food supplements such as vitamins; other food items with a health benefit; household items that were light and easy to use; telephone aids/personal alarm systems; sheltered and retirement housing or respite care; lifestyle enhancers and health insurance. Prominent themes were 
International Journal of Ageing and Later Life

health problems in older age and the benefits that the products could bring; maintenance of independence and quality of life; managing risks through having a "peace of mind"; staying younger, healthy and active; taking pride in appearance and discourses of responsibility and choice.

Underlying discourses included increased problems and risks in older age; the possibility of managing problems and regaining past pleasures; responsibility and choice of taking care of one's health and appearance with the implication of healthy and "watchable" older age (cf. the "unwatchability" of older age, Woodward 1991). On closer analysis, it seems that there are societal assumptions of relative passivity (and to some extent vulnerability) in older age and therefore the adverts strive to urge older individuals to take positive action to maintain their health and wellbeing. That this action is possible and desirable is a prominent theme.

Readers will note that we sampled a variety of magazines. One of these - Saga Magazine - is designed specifically for older people. We found that the different categories of ads are unevenly distributed between Saga and the other more general readership magazines. In fact, Saga Magazine far outstrips the others in the frequency of ads for help/ support and mobility aids whereas the general readership magazines are more likely to feature older people in ads for food and drink. This demonstrates that health messages conveyed in ads in Saga are different from those conveyed in other magazines. Although we don't see this as a major limitation to our study, subsequent research would usefully examine a wider database both in terms of number of different publications and/or number of magazine issues to add to our knowledge of health and well-being themed adverts in general readership magazines. Another useful future avenue of research would be to examine more systematically the representation of older males and females in these adverts. We have only been able to make some brief observations on gender here as it was not a focus of our analysis.

Having discussed the prominent themes in these adverts vis-à-vis ageing and health/well-being, we'd like to link our findings with current societal discourses of active ageing and anti-ageing. "Most gerontological and policy discourses pose activity as the 'positive' against which the 'negative' forces of dependency, illness and loneliness are arrayed" and it is the "medical and cultural images of an active old age that have become 
Older people's health and well-being as portrayed in UK magazine advertisements

predominant" (Katz 2000: 147, 2005). Extending the "activity discourse" to health and well-being, health in any age is seen to be achieved through one's actions and lifestyle choices relating to things such as food/nutrition and exercise. Older adults are no exception, and the adverts considered here promote continuing consumer activities that work to this end, even if the products advertised are more specialised to age-related concerns and limitations.

The abundance of products focusing on promoting and prolonging health and well-being (as well as comfort) and managing mobility and other "problems" and risks (i.e. ensuring activity) reflects the health and activity orientation to ageing of the third agers. It also relies on their continued lifestyle based on consumerism (cf. Blaikie 2006; Jones et al. 2008). It is not a coincidence that "freedom" and "independence" are prominent themes displayed through the adverts as these concepts also allude to choice as an activity. Many of the mobility and other aids are targeted to fit a niche market of relatively wealthy older consumers (which is also the case for products such as conservatories and retirement housing). An ageing cohort which is accustomed to purchasing household equipment to ease the daily chores (such as vacuum cleaners, food processors, lawnmowers, etc.), might well be expected to respond well to aids that give a promise of the maintenance of a certain quality of life.

"[M]odern individuals find that their identity comes to be challenged by their ageing body over which they wish to exert control and turn to antiageing knowledge" (Vincent 2008: 333). Adverts for food and food supplements focus on notions of staying younger, healthier, fitter or active. In other words, they focus on delaying the ageing process (at times the promises are elaborate, as in one advert which presented selenium as "the miracle mineral"). Cosmetics and more drastic treatments such as cosmetic surgery tap into notions of pride in appearance. They promise to conceal the visible effects of ageing which are assumed to be unattractive and undesirable. In other words, what is being constructed here is the body-project of the middle-aged or third-age consumer that resonates an anti-ageing ideology.

"Anti-ageing" has been defined in various ways. For example, Vincent et al. (2008: 291) cite Binstock (2004) who identifies three types of strategies 
International Journal of Ageing and Later Life

and distinguishes between "attempts to (a) slow, retard; (b) stop, halt or (c) reverse, [and] rejuvenate the ageing process". Other definitions centre on extending the life span, for example, or seeing "anti-ageing" as a social movement (Binstock 2004: 292). Our data came from magazines widely available to the general public, and not from specialist catalogues or websites of anti-ageing products. Yet the sentiments and values of combating ageing and viewing it in a biological and health frame are evident in the materials we examined. Ageing "well" is presented as slowing down ageing, not looking or feeling your age or managing agerelated risks. The positivity in the images of our adverts is achieved by depicting ageing individuals who don't look particularly old (even though they made it to our sample), that is, the majority of the images depict "young-old" individuals.

As we have seen from our analysis, some adverts - mostly those that focus on maintaining good health, delaying and/or concealing the ageing process - place responsibility, choice and control in the hands of the ageing person. It is possible that in a culture that views it as an individual responsibility to manage one's health and appearance in ageing (cf. Shilling 1993), it would be considered feckless at the very least if one didn't (cf. Featherstone and Hepworth 1993, 1995).

The question we might ask is: do older people accept the "stylised images" (Faircloth 2003) that we see in these advertisements as something they should aspire to? As has been found with respect to the gendered ageing body (Tunaley et al. 1999), increasing age could provide liberation from such moral imperatives. In other words there may well be a "freedom discourse" that older people tap into which exempts them from such responsibility. It is probably those in middle age who "buy into" the status quo but as people approach their 70s and 80s they can use increasing age as a reason to opt out. This makes us reflect on and ask what exactly "ageing well" entails: adherence to health regimens and continued attempts to control age-related problems thus responding to market forces, or stepping outside of this and refusing to treat consumerised choices as the basis for health and well-being? The second option is for obvious reasons not found in advertisements which depict older people or which are targeted at older consumers. 
Older people's health and well-being as portrayed in UK magazine advertisements

\section{Acknowledgements}

This study is part of a three-year research programme, "Images of Elders in UK Media Advertisements: Perceptions and Representations", funded by the UK Economic and Social Research Council (ESRC), Grant No. RES000-23-0416.

\section{Corresponding Author}

Virpi Ylänne, Centre for Language and Communication, Humanities Building, Cardiff University, Colum Drive, Cardiff CF10 3EU, Wales, UK. Email: ylanne@cf.ac.uk

\section{References}

Atkin, C. \& Wallack, L. (eds.). (1990). Mass Communication and Public Health. Newbury Park, CA: Sage.

Beck, U., Giddens, A. \& Lash, S. (1994). Reflexive Modernisation: Politics, Tradition and Aesthetics in the Modern Social Order. Cambridge: Polity.

Binstock, R. H. (2004). Anti-ageing medicine: The history: Anti-ageing medicine and research: A realm of conflict and profound societal implications. Journals of Gerontology Series A - Biological Sciences and Medical Sciences 59: 523-533.

Blaikie, A. (2006). Visions of later life: Golden cohort to generation Z. In J. A. Vincent, C. Phillipson \& M. Downs (eds.), The Futures of Old Age (pp. 12-19). London: Sage.

Brad Monthly Guide to Advertising Media. (2004). London: Emap Information.

Bramlett-Solomon, S. \& Wilson, V. (1989). Images of the elderly in Life and Ebony, 1978-87. Journalism Quarterly 66: 185-188.

Brubaker, C. (2007). Gender-role orientation, family structure and health behaviour: A focus on physical activity. Paper presented at the annual meeting of the American Sociological Association, New York City, August 2007.

Burchill, G., Gordon, C. \& Miller, P. (1991). The Foucault Effect: Studies in Governmentality. Harvester: London. 
International Journal of Ageing and Later Life

Bytheway, B. (2003). Visual representations of late life. In C. A. Faircloth (ed.), Aging Bodies. Images and Everyday Experience (pp. 29-53). Walnut Creek, CA: Altamira Press.

Carrigan, M. \& Szmigin, I. (1998). The usage and portrayal of older models in contemporary consumer advertising. Journal of Marketing Practice: Applied Marketing Science 4(8): 231-248.

Carrigan, M. \& Szmigin, I. (1999a). The representation of older people in advertisements. Journal of the Market Research Society 41(3): 311-326.

Carrigan M. \& Szmigin I. (1999b). Model-audience relevance in contemporary advertising: Targeting the cognitively young. Marketing and Research Today 28(1): 1-9.

Coupland, J. (2000). Ageist ideology and discourses of control in skincare product marketing. In J. Coupland \& R. Gwyn (eds.), Discourse, the Body, and Identity (pp. 127-150). Basingstoke: Palgrave Macmillan.

Coupland, J. (2007). Gendered discourses on the 'problem' of ageing: Consumerized solutions. Discourse \& Communication 1(1): 37-61.

Crawford, R. (2006). Health as meaningful social practice. Health 10(4): 401-420.

Faircloth, C. A. (2003). Different bodies and the paradox of aging: Locating aging bodies in images and everyday experience. In C. A. Faircloth (ed.), Aging Bodies: Images and Everyday Experience (pp. 1-26). Walnut Creek, CA: Altamira Press.

Fairclough, N. (2001). Language and Power. (2nd ed.). Harlow: Longman/ Pearson.

Featherstone, M. \& Hepworth, M. (1993). Images of ageing. In J. Bond \& P. Coleman (eds.), Ageing and Society: An Introduction to Social Gerontology (pp. 250-275). London: Sage.

Featherstone, M. \& Hepworth, M. (1995). Images of positive ageing. A case study of Retirement Choice magazine. In M. Featherstone \& A. Wernick (eds.), Images of Aging. Cultural Representations of Later Life (pp. 29-47). London and New York: Routledge.

Garrett, P. \& Williams, A. (2009). Age-category boundaries and social identity strategies. In M. Maegaard, F. Gregersen, P. Quist \& N. Jørgensen (eds.), Language Attitudes, Standardization and Language Change (pp. 149-162). Oslo: Novus Forlag. 
Older people's health and well-being as portrayed in UK magazine advertisements

Gergen, K. (1985). Social constructionist inquiry: Context and implications. In K. Gergen \& K. Davis (eds.), The Social Construction of the Person (pp. 3-18). New York: Springer-Verlag.

Glaser, B. G. \& Strauss, A. L. (1967). The Discovery of Grounded Theory. Strategies for Qualitative Research. New York: Aldine.

Giddens, A. (1991). Modernity and Self-identity: Self and Society in the Late Modern Age. Cambridge: Polity Press.

Gilleard, C. \& Higgs, P. (2000). Cultures of Ageing. Self, Citizen and the Body. Harlow: Prentice Hall/Pearson Education.

Harwood, J. \& Anderson, K. (2002). The presence and portrayal of social groups on prime-time television. Communication Reports 15(2): 81-97.

Harwood, J. \& Giles, H. (1992). 'Don't make me laugh': Age representations in a humorous context. Discourse \& Society 3(3): 403-436.

Harwood, J. \& Roy, A. (1999). The portrayal of older adults in Indian and U.S. magazine advertisements. The Howard Journal of Communications 10: $269-280$.

Hughes, B. (2000). Medicalised bodies. In P. Hancock, B. Hughes, E. Jagger, K. Paterson, R. Russell, E. Tulle-Winton \& M. Tyler (eds.), The Body, Culture and Society (pp. 45-63). Buckingham: Open University Press.

Hummert, M. L., Garstka, T. A., Shaner, J. L. \& Strahm, S. (1994). Stereotypes of the elderly held by young, middle-aged, and elderly adults. Journal of Gerontology: Psychological Sciences 49: 240-249.

Jolanki, O. (2008). Discussing responsibility and ways of influencing health. International Journal of Ageing and Later Life 3(1): 45-76.

Jones, I. R., Hyde, M., Victor, C. R., Wiggins, R. D., Gilleard, C. \& Higgs, P. (eds.). (2008). Ageing in a Consumer Society. From Passive to Active Consumption in Britain. Bristol: Policy Press.

Katz, S. (2000). Busy bodies: Activity, aging and the management of everyday life. Journal of Aging Studies 14(2): 135-152.

Katz, S. (2005). Cultural Aging. Life Course, Lifestyle, and Senior Worlds. Peterborough, ON: Broadview.

Kessler, E-M., Rakoczy, K. \& Staudinger, U. M. (2004). The portrayal of older people in prime time television series: The match with gerontological evidence. Ageing and Society 24: 531-552.

Kress, G. \& van Leeuwen, T. (1996). Reading Images. The Grammar of Visual Design. London and New York: Routledge. 
International Journal of Ageing and Later Life

Laslett, P. (1996). A Fresh Map of Life: The Emergence of the Third Age (2nd ed.). Basingstoke: Macmillan.

Lee, M., Carpenter, B. \& Meyers, L. S. (2007). Representations of older adults in television advertisements. Journal of Aging Studies 21(1): 23-30.

Mautner, G. (2007). Mining large corpora for social information: The case of elderly. Language in Society 36: 51-72.

McKay, S. (2003). The paradox in ageing well: Stories of older women in the Australian Women's Weekly. Journal of Media \& Cultural Studies 17(2): 177-185.

Miller, D. W., Leyell, T. S. \& Mazachek, J. (2004). Stereotypes of the elderly in U.S. television commercials from the 1950s to the 1990s. International Journal of Aging and Human Development 58(4): 315-340.

Miller, P. N., Miller, D. W., McKibbin, E. M. \& Pettys, G. L. (1999). Stereotypes of the elderly in magazine advertisements 1956-1996. International Journal of Aging and Human Development 49(4): 319-337.

National Readership Survey. (2003). London: National Readership Survey Ltd.

Peterson, R. T. (1992). The depiction of senior citizens in magazine advertisements: A content analysis. Journal of Business Ethics 11: 701706.

Peterson, R. T. (1995). The portrayal of senior citizens by banks in newspaper advertisements: A content analysis. Journal of Professional Services Marketing 12(2): 95-106.

Piotrow, P. T., Kincaid, D. L., Rimon, J. G. \& Ward, R. (1997). Health Communication. Westport, CT: Praeger.

Roberts, S. D. \& Zhou, N. (1997). The 50 and older characters in the advertisements of Modern Maturity: Growing older, getting better? Journal of Applied Gerontology 16(2): 208-220.

Robinson, J. D. \& Skill, T. (1995). The invisible generation: Portrayals of the elderly on prime-time television. Communication Reports 8: 111-119.

Robinson, J. D., Skill, T. \& Turner, J. W. (2004). Media usage patterns and portrayals of seniors. In J. F. Nussbaum \& J. Coupland (eds.), Handbook of Communication and Aging Research (pp. 423-446). Mahwah, NJ: Lawrence Erlbaum.

Robinson, T., Gustafson, B. \& Popovich, M. (2008). Perceptions of negative stereotypes of older people in magazine advertisements: Comparing 
Older people's health and well-being as portrayed in UK magazine advertisements

the perceptions of older adults and college students. Ageing and Society 28: 233-251.

Roy, A. \& Harwood, J. (1997). Underrepresented, positively portrayed. Older adults in television commercials. Journal of Applied Communication Research 25: 39-56.

Rozanova, J. (2006). Newspaper portrayals of health and illness among Canadian seniors: Who ages healthily and at what cost? International Journal of Ageing and Later Life 1(2): 111-139.

Saltonstall, R. (1993). Healthy bodies, social bodies: Men's and women's concepts and practices of health in everyday life. Social Science and Medicine 36(1): 7-14.

Shilling, C. (1993). The Body and Social Theory. London: Sage.

Simcock, P. \& Sudbury, L. (2006). The invisible majority? Older models in UK television advertising. International Journal of Advertising 25(1): $87-106$.

Smythe, T. C. (1996). Growing old in commercials: A joke not shared. In P. Lester (ed.), Images that injure: Pictorial stereotypes in the media (pp. 113-116). London: Praeger.

Strauss, A. \& Corbin, J. (1998). Basics of Qualitative Research (2nd ed.). Thousand Oaks, CA: Sage.

Swayne, L. E. \& Greco, A. J. (1987). The portrayal of older Americans in television commercials. Journal of Advertising 16(1): 47-54.

Tunaley, J., Walsh, S. \& Nicolson, P. (1999). I'm not bad for my age: The meaning of body size and eating in the lives of older women. Ageing and Society 19: 741-759.

Turner, B. (1995). Medical Power and Social Knowledge (2nd ed.). London: Sage.

Ursic, A. C., Ursic, M. L. \& Ursic, V. L. (1986). A longitudinal study of the use of the elderly in magazine advertising. Journal of Consumer Research 13: 131-133.

Vincent, J. A. (2008). The cultural construction of old age as a biological phenomenon: Science and anti-ageing technologies. Journal of Aging Studies 22: 331-339.

Vincent, J. A., Tulle, E. \& Bond, J. (2008). The anti-ageing enterprise: Science, knowledge, expertise, rhetoric and values. Journal of Aging Studies 22: 291-294. (Editorial for a special issue on Anti-ageing) 
International Journal of Ageing and Later Life

Williams, A., Wadleigh, P. M. \& Ylänne, V. (in press). Images of older people in UK magazine advertising: Towards a typology. International Journal of Aging and Human Development.

Williams, A., Ylänne, V. \& Wadleigh, P. M. (2007). Selling the 'elixir of life': Images of the elderly in an Olivio advertising campaign. Journal of Aging Studies 21(1): 1-21.

Williams, A., Ylänne, V., Wadleigh, P. M. \& Chen, C.-H. (2010). Portrayals of older adults in UK magazine advertisements: Relevance of target audience. To appear in Communications: The European Journal of Communication Research 35(1): 1-27.

Willing's Press Guide to UK Media. (2003). Chesham, Bucks. UK: Romeike Ltd.

Winter, E. O. (1982). Towards a Contextual Grammar of English: The Clause and Its Place in the Definition of Sentence. London: Allen and Unwin.

Woodward, K. (1991). Aging and its Discontents. Freud and Other Fictions. Bloomington, IN and Indianapolis, IN: Indiana University Press. 